\section{Notes and activities}

\section{5th International Update on Liver \\ Disease}

This meeting will be held at the Royal Free Hospital, London, 17-19 July 1980. Speakers include: G D Bell (Nottingham), P D Berk (New York), H Conn (Yale), D G James (London), I Mackay (Melbourne), H Popper (New York), T B Reynolds (Los Angeles), J Rodes (Barcelona), F Schaffner (New York), P J Scheuer (London), A J Zuckerman (London), and staff of the Medical Unit of the Royal Free Hospital. Topics include molecular biology, immunology, granulomas, fatty liver, portal hypertension, collagen, non-A non-B hepatitis, ascites, therapeutic radiology, slide seminar, and case discussions. For registrations (limited) apply to Professor Dame Sheila Sherlock, Royal Free Hospital, Pond Street, London NW3 2QG.

\section{6th International Bile Acid Meeting}

This meeting will be held at Freiburg/Br. West Germany, 9-11 October 1980. Details may be obtained from G Paumgartner, MD, Department of Internal Medicine II, University of Munich, Marchioninistrasse 15, D-8000 Munich 70, W. Germany.

\section{World Congresses of Gastroenterology (with Digestive Endoscopy and Colo- proctology)}

These will be held in Stockholm, 14-19 June 1982. (Organisation Mondiale de Gastroenterologie.) President: Göran Lundh, Secretary General: Dag Hallberg. Details from c/o Stockholm Convention Bureau, Jakobs Torg 3, S-111 52 Stockholm, Sweden. (Telex: 11556 congress.)

\section{Books}

Pathways in surgical management By Michael Hobsley. (Pp. 343. Illustrated. £13.75). Edward Arnold: Maidenhead. 1979.

In clinical practice there are a limited number of recurring problems and Professor Hobsley picks out 18 common nonemergency conditions, such as dysphagia, palpable abdominal mass, and 10 common emergency situations, such as acute blood loss, or pain in the right iliac fossa. He constructs flow charts illustrating the process of thought and action and how steps should follow in logical sequence. The idea is interesting and sensible. The patient provides a symptom or clinical sign and not a diagnostic label and the doctor has to work from there in the fewest possible steps to achieve the diagnosis and take appropriate action. The traditional approach is to teach comprehensively about the final diagnosis and its manifestations. This surely remains essential, but there is a great deal to be said for the student learning much of this himself, as he can do from textbooks, and this becomes much more interesting if the reading is dictated by steps in the flow-path.

The traditional approach is to teach the important differential diagnoses in relation to a clinical picture. Professor Hobsley looks at the process of diagnosis, or management decision, as sequential and which ideally should follow the shortest and most economical pathway. This contrasts with the wide range of investigations to cover most possibilities in differential diagnoses. With the NHS under financial strain there is no doubt that, with the Hobsley flowpath approach, better use might be made of present resources. Excellent though the idea is, however, his sequential analysis tends to get lost in much conventional dissertation about causal processes and their many manifestations. Standard textbooks cannot be dispensed with, but could be complementary to the flow-pattern approach. If this were accepted, then his book could be shorter, more precise, and would then be equally appropriate for doctors in practice as well as in training. F AVERY JONES

Nutrition and drug interrelations Edited by J. N. Hathcock and J. Coon. (Pp. 927. Illustrated, \$55.00; £35.) Academic Press: London. 1978.

This Nutrition Foundation monograph contains 29 chapters based on papers presented at an international symposium held in Iowa in 1976. The book is divided into four sections. The first-drug effects on nutrient intake, function, and requirement-contains Ivey's concise account of the pathogenesis and drug treatment of gastric mucosal damage, in which nutrition is not mentioned. Chhabra and Tredger's 20 page chapter on inter- actions of drugs and intestinal mucosa endoplasmic reticulum contains one page

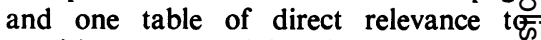
nutrition and Prin's chapter on the nutritional impact of intestinal drug@ microbe interactions deals very thoroughles with ruminants, but only briefly with man.

The second section-nutritional effects on drug metabolism and action-includes. Roe's clear account of the influence of food on drug absorption and drug-foo incompatibilities, which stands out as on $\mathrm{e}^{+}$ of the most readable chapters in the book Rogers' chapter reviews the evidence that dietary intake modifies the response to carcinogenic therapeutic agents and out $\delta$ lines the requirement for further work which might lead to protective dietary measures. The third section deals with the use of drugs in animal feeds, while the fourth-use of nutrients and food as drug -includes Schonfeld and Witztun's fu迹 account of the development of atherosclerosis and the hyperlipoproteinaemiaso followed by a review of dietary and drug therapy. The final chapter is a superficiag review of the medicinal uses of foods.

Extensive references follow each chap ter, most being dated not later than 1976\% though some for 1977 have been inserted The subject and author indexes are extensive but the author index is no్ㅡㅁ complete-at least one reference is missing from the listing. This book would be useful reference v'ork for physicians bư? parts of it may only be of interest t@ pharmacologist i

ANTHONY R LEEDS

Techniques of vagotomy By A. G尺 Johnson and K. W. Reynolds. (Pp. 85? Illustrated. £5.95.) Edward Arnold: Long don. 1979.

This short book is an excellent guide tơ the different vagotomy procedures for the surgeon in training. The text is brief and contains many of the author's ideas and details of technique.

The illustrations are clear and drawe from the surgeon's view.

The three main vagotomy techniques and gastric drainage operations are described; the problems and main points of each procedure are highlighted. Intraoperative tests for completeness of vagotomy are also discussed.

N MENZIES GOV尺 